\title{
Is Gap Index Better Than Cast Index as a Predictor of Redisplacement of Paediatric Forearm and Extra-Articular Distal Radius Fracture Treated by Plaster Casting
}

\author{
Ranjit Shaw ${ }^{1}$, Prabir Kumar Dutta2 ${ }^{2}$, Mainak Chandra ${ }^{3}$, Kaushik Banerjee ${ }^{4}$, Md Emdad Hossain ${ }^{5}$ \\ 1, 2,3,4,5 Department of Orthopaedics, R.G. Kar Medical College and Hospital, Kolkata, West Bengal, India.
}

\section{ABSTRACT}

\section{BACKGROUND}

Although closed fractures of the forearm in children are often treated with closed reduction and immobilisation in a well-fitting plaster cast and achieve a satisfactory outcome in a majority of patients, redisplacement of these fractures remains a complication. The rates of redisplacement as high as $25 \%$ have been quoted and several authors advocate surgical fixing of high risk forearm fractures. An important modifiable risk factor for fracture redisplacement is the quality of casting, which can be measured objectively by the use of casting indices. Cast index (CI), described by Chess et al. and the gap index, are two described radiological indices to identify a poorly applied plaster. Our study was undertaken with the aim of comparing the final outcome in paediatric forearm fracture radiologically with regard to cast index and gap index as a predictor of redisplacement.

\section{METHODS}

A longitudinal study of 100 indoor and outdoor paediatric patients with extraarticular distal radius fracture who received conservative treatment was done. Cast and gap indices were measured and on follow up, redisplacement, time to achieve union, and non-union were assessed.

\section{RESULTS}

The mean cast index of the redisplacement group was 0.84 , which significantly differs $(\mathrm{P}<0.001)$ from the control group at 0.68 . The gap index was higher $(\mathrm{P}<0.001)$ in the redisplacement group than in the control group both in the anteroposterior and in the lateral views. The mean cast index of the non-union group was 0.875 , which significantly differs $(\mathrm{P}<0.001)$ from the control group at 0.685 . The gap index was higher $(\mathrm{P}<0.001)$ in the non-union group than in the control group both in the antero-posterior ( 0.132 vs. 0.068$)$ and in the lateral ( 0.112 vs. 0.057$)$ views.

\section{CONCLUSIONS}

Our study showed that that gap index was associated with re-displacement more closely than cast index, even on multivariate analysis after adjusting for additional ulnar fracture and poor cast maintenance.

\section{KEY WORDS}

Paediatric Forearm Fractures, Cast Index, Gap Index
Corresponding Author: Dr. Mainak Chandra, Assistant Professor, Department of Orthopaedics, R.G. Kar Medical College and Hospital, Kolkata, West Bengal, India. E-mail: mainakchandra@yahoo.co.in

\section{DOI: $10.14260 /$ jemds/2021/58}

How to Cite This Article:

Shaw R, Dutta PK, Chandra M, et al. Is gap index better than cast index as a predictor of redisplacement of paediatric forearm and extra - articular distal radius fracture treated by plaster casting. J Evolution Med Dent Sci 2021;10(05):258-263, DOI: $10.14260 / \mathrm{jemds} / 2021 / 58$

Submission 24-01-2020,

Peer Review 24-11-2020,

Acceptance 30-11-2020,

Published 01-02-2021.

Copyright (C) 2021 Ranjit Shaw et al. This is an open access article distributed under Creative Commons Attribution License [Attribution 4.0 International (CC BY 4.0)] 


\section{BACKGROUND}

Forearm fractures are among the most commonly encountered fractures in the paediatric age group after fracture clavicle. ${ }^{1}$ Distal radius fractures are the most common limb fractures in childhood, accounting for $20-30 \%$ of all limb fractures. ${ }^{2}$ Proximal forearm fractures account for 16 $24 \%$ of all paediatric forearm fractures. The majority of these fractures occur in children aged over 5 years, usually sustained by direct trauma to the upper limb.

The incidence of fractures peaks in girls aged $9-12$ years and boys aged $12-15$ years at the time of the pubertal growth spurt.3,4

Closed fractures of the forearm in children are often treated with closed reduction and immobilisation in a wellfitting plaster cast and achieve a satisfactory outcome in a majority of patients. Fixation is generally reserved for unstable fractures, failed reduction and complications such as open fractures or those associated with compartment syndrome. Distal radius fractures in children heal quickly and mild to moderate degrees of displacement can be accepted as bone remodelling during early childhood has the potential to correct deformities. ${ }^{4}$

However, in children aged over 9 years a reduced potential for remodelling means that lesser degrees of deformity are acceptable. Redisplacement of these fractures remains a complication. The rates of redisplacement as high as $25 \%$ have been quoted and several authors advocate surgical fixing of high risk forearm fractures. . $^{3-5}$

Distal radius fractures in children are well recognised for re-displacement after manipulation. Variable rates of redisplacement have been reported ranging from 7 to $39 \%{ }^{6-10}$ Several studies have looked into the causes of this loss of position. Factors include a non-anatomical reduction, the position of the forearm after manipulation, the inclusion of the elbow in the plaster, the pre-manipulation displacement and the seniority of the surgeon.6,8,11-17

Previous studies have consistently shown that the most important risk factor for redisplacement of a forearm fracture is the initial displacement of the fracture. ${ }^{7,13,14}$ Other factors that are important in redisplacement include distance of the fracture from the physis, obliquity of the fracture, inadequate initial closed reduction, poor cast moulding and resolution of oedema whilst in the cast.

An important modifiable risk factor for fracture redisplacement is the quality of casting, which can be measured objectively by the use of casting indices. The first and simplest index to be described is the cast index (CI), described by Chess et al. ${ }^{17}$ It is calculated by measuring the internal antero-posterior (AP) diameter of the cast (including padding) at the level of the fracture and dividing it by the internal lateral diameter of the cast (including padding).

Both measurements are made using the first proper radiograph taken after closed reduction and the calculation results in a numerical ratio. Chess et al. initially described an ideal $\mathrm{CI}$ to be 0.7 at the distal radius based on anthropomorphic studies, but more recent studies have shown a CI of over $0.8-0.84$ carries a significant risk of redisplacement that is, a poorly moulded cast (as seen on the lateral radiograph view) is more likely to allow the fracture to displace. ${ }^{18,19}$ Both of these studies included patients with radius with or without ulnar fractures. Debnath et al. included patients with proximal and distal forearm fractures, whereas Bhatia and Housden focused on distal forearm fractures. ${ }^{18,19}$

Poor moulding of the plaster and excessive padding is a recognised cause of a loose-fitting plaster leading to redisplacement. The cast index ${ }^{13,17}$ has been previously described as a radiological measure of moulding of the plaster. Another radiological index, the gap index, has recently been proposed as a tool to identify a poorly applied plaster. The gap index is a measure of poor moulding and excessive padding applied before plaster application. ${ }^{20}$

Hence, a study was undertaken with the aim of comparing the final outcome in paediatric forearm fracture radiologically in respect with cast index and gap index as a predictor of redisplacement.

Specific objectives to find out, among the paediatric patients presenting with forearm fracture

1. Predictive outcome of fracture union in respect of gap index.

2. Predictive outcome of fracture union in respect of cast index

3. Final comparison of two indices in fracture union \& redisplacement.

\section{METHODS}

It was an institution based, longitudinal study conducted in the Dept. of Orthopaedics, R.G. Kar Medical College and Hospital. from June 2015 to July 2016.

100 Indoor and outdoor paediatric patients with extraarticular distal radius fracture who received conservative treatment and continued follow up visit were recruited for study using following inclusion \& exclusion criteria. Informed consent (parental assent) was taken from all cases. Approval was taken from institutional ethical committee

\section{Inclusion Criteria}

The paediatric patients who had the following characteristics:

- $\quad$ Age: 2 Yrs. -12 Yrs.

- $\quad$ Closed fracture.

- Distal radius fracture.

- Associated ulnar fracture.

- Extraarticular fractures.

\section{Exclusion Criteria}

- Old nonunited fractures.

- Associated other major fractures.

- Fractures with distal neurovascular deficit.

- Chronic debilitating diseases / malnutrition / endocrinopathy.

\section{Study Tools}

1. History and clinical examinations.

2. Radiograph: Antero-postero view, lateral. view,

3. Plastering materials: Plaster of Paris (P.O.P) bandage, roller cotton and bandages, c-c sling.

4. Anaesthetic equipment's and drugs. 


\section{Parameters to Be Studied}

Clinical

1. Pain and tenderness at the fracture site.

2. Movements in between fracture ends.

\section{Radiological}

1. Antero-postero view, lateral, view.

2. Gap index and cast index.

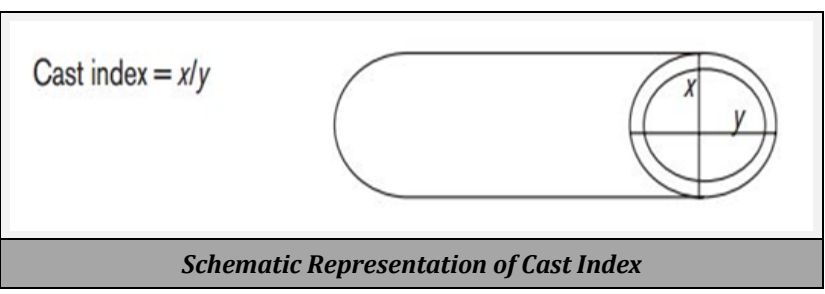

- $\mathrm{X}=$ inner width of the cast in lateral view,

- $\quad \mathrm{Y}=$ inner width of the cast in AP view.

(All measured from true size skiagram)

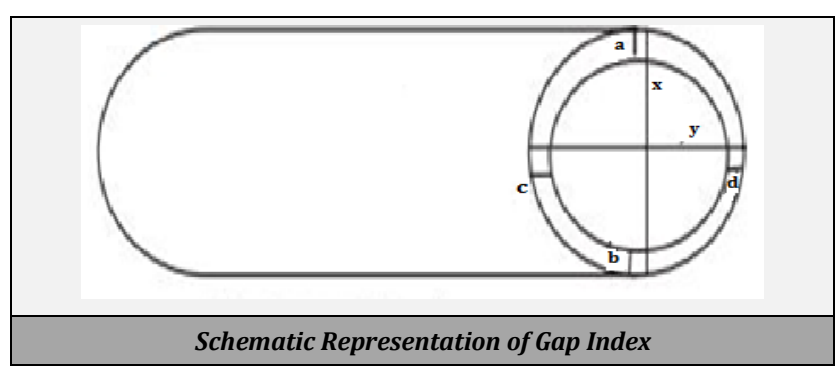

Calculation of gap index $=$

Lat view $=(a+b) / x$

AP view $=(c+d) / y$

Gap Index (sum) i.e., $[(a+b) / x+(c+d) / y]$

- $\quad \mathrm{a}=$ Width of cotton padding dorsally in lateral view,

- $\quad b=$ Width of cotton padding volarly in lateral view

- $\quad c=$ Width of cotton padding on radial side in AP view

- $\mathrm{d}=$ Width of cotton padding on ulnar side in AP view

(All measured from true size skiagram)

\section{Assessment in Follow Up \\ 1. Redisplacement. \\ 2. Time to achieve union \\ 3. Non-union, if any}

\section{Study Technique}

Forearm fracture is associated with biomechanical changes and serious functional impairment involving forearm and joints. Bone union, restoration of fracture architecture, relief of pain, re-establishment of limb function was considered the primary goal. Follow up was done 2 weekly initially. Improvement was assessed clinically as well as radiologically for the assessment of the fracture displacement after manipulation and casting.

\section{Statistical Analysis}

All the data were initially entered into MS Excel ${ }^{\circledR}$ and later the spreadsheets were used for analyses. Statistical analysis was done using SPSS $^{\odot}$ version 20.0. The data was analysed using standard statistical methods. Different parameters (as per specific objectives) were evaluated using methods comparable to those used for similar studies in the past. Results were presented using charts, graphs, tables, diagrams, photographs. Student's t-test was applied to compare the mean between two groups. Receiver operating characteristic (ROC) curve analyses and test of sensitivity and specificity were done to validate the indices for prediction of optimum non-surgical reduction. For all statistical tests of significance, P-value less than 0.05 was considered to reject the null hypothesis.

\section{RESULTS}

\begin{tabular}{|ccc|}
\hline Age in Completed Years & Frequency & Percent \\
2 & 5 & 5.0 \\
3 & 9 & 9.0 \\
4 & 15 & 15.0 \\
5 & 12 & 12.0 \\
6 & 14 & 14.0 \\
7 & 15 & 15.0 \\
8 & 11 & 11.0 \\
9 & 11 & 11.0 \\
10 & 2 & 2.0 \\
11 & 4 & 4.0 \\
12 & 2 & 2.0 \\
\hline Table 1. Age Distribution in the Study Population (N = 100) \\
N.B.: Mean age: 6.21 yrs., median age: 6.00 years, SD: 2.442 males: 70 \\
females: 30 & & \\
\hline
\end{tabular}

\begin{tabular}{|c|c|c|c|c|c|}
\hline & $\begin{array}{c}1 \\
\text { Week }\end{array}$ & $\begin{array}{c}2 \\
\text { Weeks }\end{array}$ & $\begin{array}{c}4 \\
\text { Weeks }\end{array}$ & $\begin{array}{c}6 \\
\text { Weeks }\end{array}$ & $\begin{array}{l}\text { Total, at the End } \\
\text { of Study }\end{array}$ \\
\hline $\begin{array}{l}\text { Re-displacement } \\
\text { present }\end{array}$ & 5 & 6 & 6 & 2 & 19 \\
\hline $\begin{array}{c}\text { Re-displacement } \\
\text { absent }\end{array}$ & 95 & 87 & 81 & 79 & 79 \\
\hline \multicolumn{6}{|c|}{$\begin{array}{l}\text { Table 2. Incidence of Re-Displacement at Various Visits } \\
\qquad(N=100 \text { Initially) }\end{array}$} \\
\hline
\end{tabular}

\begin{tabular}{|cccc|}
\hline Parameter & $\begin{array}{c}\text { Re-Displacement } \\
\text { Present (N = 19) } \\
\text { Mean (SD) }\end{array}$ & $\begin{array}{c}\text { No Re-Displacement } \\
\text { (N = 79) Mean (SD) }\end{array}$ & P-Value \\
\hline $\begin{array}{c}\text { Cast index } \\
\text { Gap index antero- } \\
\text { posterior }\end{array}$ & $0.836(0.111)$ & $0.680(0.080)$ & $<0.001$ \\
Gap index lateral & $0.131(0.036)$ & $0.064(0.017)$ & $<0.001$ \\
Gap index sum & $0.112(0.026)$ & $0.053(0.018)$ & $<0.001$ \\
\hline \multicolumn{4}{|c|}{ Table 3. Comparison of Cast Index and Gap Index between } \\
\multicolumn{4}{|c|}{ Patients with and without Re-Displacement. } \\
\hline
\end{tabular}

\begin{tabular}{|cccc|}
\hline Parameter & $\begin{array}{c}\text { Non-Union } \\
\text { Present (N = 14) } \\
\text { Mean (SD) }\end{array}$ & $\begin{array}{c}\text { No Non-Union } \\
(\mathbf{N}=\mathbf{8 4}) \text { Mean (SD) }\end{array}$ & P-Value \\
\hline $\begin{array}{c}\text { Cast index } \\
\text { Gap index antero- } \\
\text { posterior }\end{array}$ & $0.875(0.085)$ & $0.685(0.085)$ & $<0.001$ \\
Gap index lateral & $0.132(0.030)$ & $0.068(0.026)$ & $<0.001$ \\
Gap index sum & $0.112(0.026)$ & $0.057(0.024)$ & $<0.001$ \\
\hline \multicolumn{4}{|c|}{ Table 4. Comparison of Cast Index and Gap Index between } \\
\multicolumn{4}{|c|}{ Patients with and without Non-Union. } \\
\hline
\end{tabular}

\begin{tabular}{|c|c|c|}
\hline & $\begin{array}{cc}\text { Re-Displacement } & \text { Re-Displacement } \\
\text { Present } & \text { Absent }\end{array}$ & Total \\
\hline $\begin{array}{l}\text { High cast index } \\
\text { value }(\geq 0.78)\end{array}$ & 14 (TP) & 21 \\
\hline $\begin{array}{l}\text { Low cast index } \\
\text { value }(<0.78)\end{array}$ & $72(\mathrm{TN})$ & 77 \\
\hline Total & 79 & 98 \\
\hline \multicolumn{3}{|c|}{$\begin{array}{c}\text { Table 5. Cross-Tabulation of High Cast Index }(\geq 78) \\
\text { and Re-Displacement }(N=98)\end{array}$} \\
\hline \multicolumn{3}{|c|}{$\begin{array}{l}\text { Sensitivity: TP } * 100 /(\mathrm{TP}+\mathrm{FN})=1400 /(14+5)=73.68 \% \\
\text { Specificity: } \mathrm{TN} * 100 /(\mathrm{TN}+\mathrm{FP})=7200 /(72+7)=91.14 \% \\
\text { Positive predictive value: } \mathrm{TP} * 100 /(\mathrm{TP}+\mathrm{FP})=1400 /(14+7)=66.67 \\
\% \text { Negative predictive value: } \mathrm{TN} * 100 /(\mathrm{TN}+\mathrm{FN})=7200 /(72+5)= \\
93.51 \%\end{array}$} \\
\hline
\end{tabular}



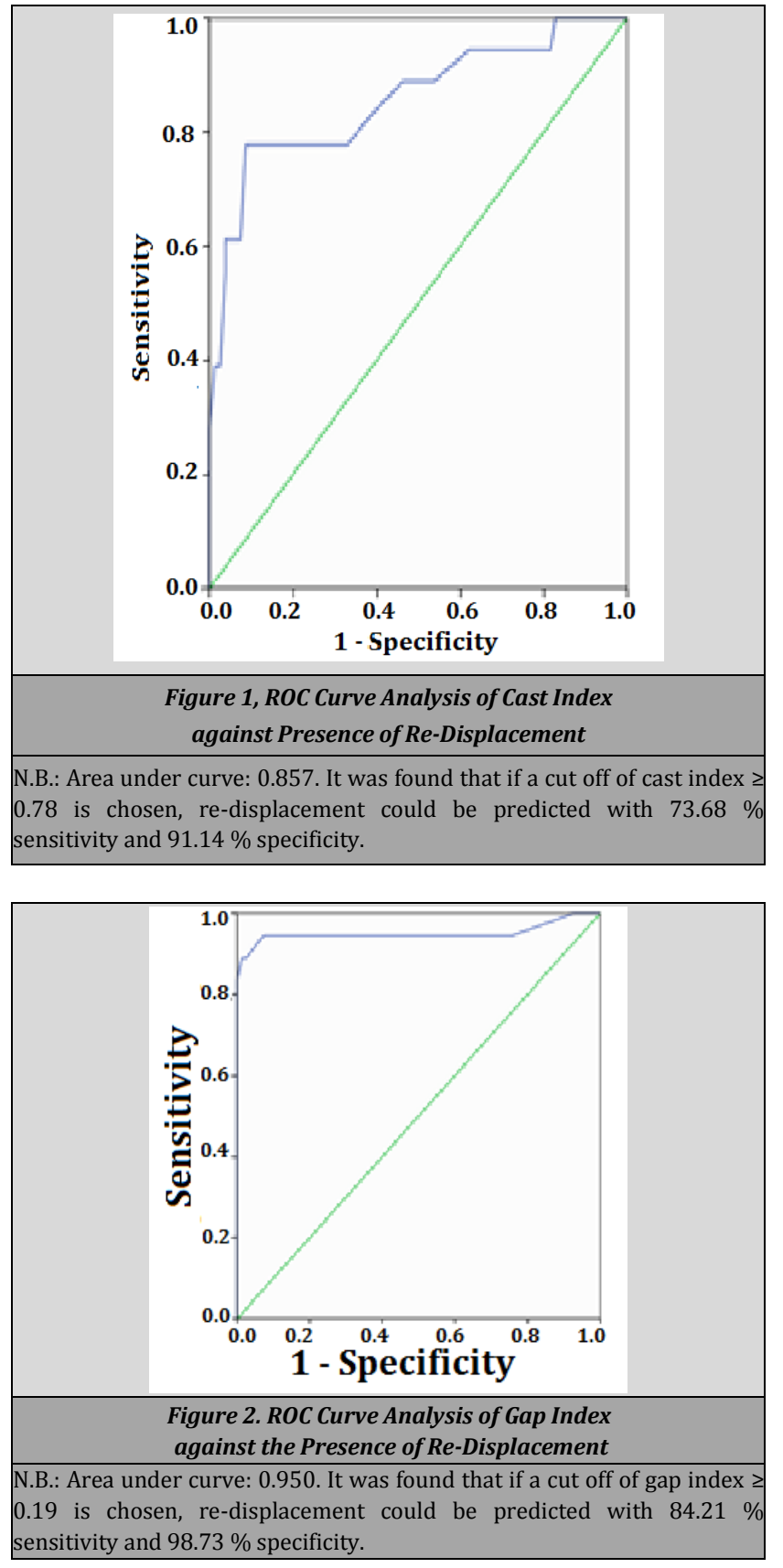

The mean age of the redisplacement group was 6.5 years, which was similar $(\mathrm{P}=0.56)$ to the control group at 6.13 years. Male to female ratio was considerably higher in the failure group than in the control group though the association was not statistically significant. The adequacy of reduction after manipulation in both the groups was estimated by the postreduction translation and angulations of the radius in lateral and AP views. No significant difference was noted between the two groups except the shift in lateral angulation.

All the patients had an above elbow plaster following manipulation and in these, the plaster split following manipulation was not observed in any of the cases. The mean cast index of the redisplacement group was 0.84 , which significantly differs $(\mathrm{P}<0.001)$ from the control group at 0.68 . The gap index was higher $(\mathrm{P}<0.001)$ in the redisplacement group than in the control group both in the antero-posterior and in the lateral views.

The mean cast index of the non-union group was 0.875 , which significantly differs $(\mathrm{P}<0.001)$ from the control group at 0.685 (Table 4). The gap index was higher $(\mathrm{P}<0.001)$ in the non-union group than in the control group both in the anteroposterior (0.132 vs. 0.068$)$ and in the lateral ( 0.112 vs. 0.057$)$ views.

The scatter plots showing distribution of the cast index and the gap index suggest that there is a clearer distinction between the two groups when considering the gap index in contrast to the more even distribution of the cast index. This seems to be corroborated by the higher values for the gap index than for the cast index in predicting failure.

The sensitivity, specificity, positive and negative predictive values, the accuracy and the odds ratio of the two tests to predict failure of treatment are depicted in Table 5.

\section{DISCUSSION}

Cast Index and Gap Index are measured from immediate post reduction skiagram. Those found to redisplaced in follow up were virtually considered as control for comparison, though no actual control group as incorporated in the study.

The mean age of the failure (redisplacement) group was 6.5 years, which was similar $(\mathrm{P}=0.56)$ to the control group at 6.13 years.

Male to female ratio was considerably higher in the failure group than in the control group though the association was not statistically significant.

The adequacy of reduction after manipulation in both the groups was estimated by the post-reduction translation and angulations of the radius in lateral and AP views. No significant difference was noted between the two groups except the shift in lateral angulation.

All the patients had an above elbow plaster following manipulation and in these, the plaster split following manipulation was not observed in any of the cases.

The mean cast index of the redisplacement group was 0.84 , which significantly differs $(\mathrm{P}<0.001)$ from the control group at 0.68 (Table 3). The gap index was higher $(\mathrm{P}<0.001)$ in the redisplacement group than in the control group both in the anteroposterior and in the lateral views (Table 3).

The mean cast index of the non-union group was 0.875 , which significantly differs $(\mathrm{P}<0.001)$ from the control group at 0.685 (Table 4$)$. The gap index was higher $(\mathrm{P}<0.001)$ in the non-union group than in the control group both in the anteroposterior (0.132 vs. 0.068$)$ and in the lateral (0.112 vs. 0.057$)$ views (Table 4).

The sensitivity, specificity, positive and negative predictive values, the accuracy and the odds ratio of the two tests to predict failure of treatment are depicted in Table 5.

It is evident that Gap index was associated with redisplacement more closely than cast index, even on multivariate analysis after adjusting for additional ulnar fracture and poor cast maintenance.

The above findings from the study lead to analysis of existing articles on the relatively novel topic. Treatment of distal radial fractures has always been controversial because of the high failure rate of closed treatment. Closed reduction of paediatric forearm fractures followed by long arm plaster has been reported to be the accepted standard and the technique of pins and plaster should be considered a reliable alternative for the unstable injuries when acceptable alignment after 
manipulation cannot be achieved or maintained. ${ }^{15-18}$ Some suggest that percutaneous wire fixation is a safe, convenient, effective and reliable means to maintain alignment ${ }^{21,18}$ and, considering the high re-displacement rate, recommend that all isolated distal radius fractures in children requiring manipulations should have percutaneous wire fixation.12,19 Our unit reserves stabilization by K-wires for only those fractures that remain unstable after a manipulation. This study only includes patients who were treated by closed reduction under anaesthesia followed by plaster application. A belowelbow plaster has previously been reported to be adequate in the treatment of distal paediatric forearm fractures if attention is paid to the proper moulding of the cast. ${ }^{11}$ All the patients in our study, however, were treated by an above elbow plaster. Forearm position during cast immobilization was initially thought to be a significant factor in preventing redisplacement, 9,10 but studies have shown that it is probably not related to the final outcome. ${ }^{20} \mathrm{We}$, therefore, did not include this parameter in this study. Fractures with complete initial displacement and those involving both the radius and ulna have been identified as risk factors for re-displacement ${ }^{12}$ and therefore require more careful follow-up. ${ }^{6}$ Mani et al. ${ }^{3}$ reported that translation of the radius of more than half the diameter of the bone was associated with a risk of failure of 60 $\%$, compared with $8 \%$ for fractures with less translation Haddad and Williams. ${ }^{7}$ felt that the most favourable factor was achieving a perfect anatomical alignment on the immediate post reduction radiographs. This would in turn depend on the seniority and experience of the surgeon. Indeed, it has been reported that the remanipulation rate depends on the grade of surgeon and the time of manipulation. ${ }^{1}$ Poorly applied plaster is a well-recognized cause of failure of treatment and both the cast and the gap index measure this.

\section{CONCLUSIONS}

Gap index is associated with re-displacement more closely than cast index, even on multivariate analysis after adjusting for additional ulnar fracture and poor cast maintenance.

\author{
Limitations of Our Study \\ 1. Absence of comparison group. \\ 2. Longitudinal design. \\ 3. No scope for adjusting in case of human error in \\ treatment provided. \\ 4. Small sample size. \\ 5. Unicentric study.
}

Data sharing statement provided by the authors is available with the full text of this article at jemds.com.

Financial or other competing interests: None.

Disclosure forms provided by the authors are available with the full text of this article at jemds.com.

We would like to acknowledge the administration of R G Kar Medical College and Hospital for their cooperation and in helping us get ethical committee clearance for this study. Above all, to all the young children and their parents who were patient throughout the period of study and during follow-up.

\section{REFERENCES}

[1] Cheng JC, Shen WY. Limb fracture pattern in different pediatric age groups: a study of 3,350 children. J Orthop Trauma 1993;7(1):15-22.

[2] Carson S, Woolridge DP, Colletti J, et al. Pediatric upper extremity injuries. Pediatr Clin North Am 2006;53(1):4167, v.

[3] Zamzam MM, Khoshhal KI. Displaced fracture of the distal radius in children: factors responsible for redisplacement after closed reduction. J Bone Joint Surg $\mathrm{Br}$ 2005;87(6):841-3.

[4] Hove LM, Brudvik C. Displaced paediatric fractures of the distal radius. Arch Orthop Trauma Surg 2008;128(1):5560.

[5] Garg NK, Ballal MS, Malek IA, et al. Use of elastic stable intramedullary nailing for treating unstable forearm fractures in children. J Trauma 2008;65(1):109-15.

[6] Proctor MT, Moore DJ, Paterson JM. Redisplacement after manipulation of distal radial fractures in children. J Bone Joint Surg Br 1993;75(3):453-4.

[7] Alemdaroğlu KB, Iltar S, Cimen 0, et al. Risk factors in redisplacement of distal radial fractures in children. J Bone Joint Surg Am 2008;90(6):1224-30.

[8] Chan CF, Meads BM, Nicol RO. Re-manipulation of forearm fractures in children. NZ Med J 1997;110(1047):249-50.

[9] Voto SJ, Weiner DS, Leighley B. Redisplacement of forearm fractures in children. J Pediat Orthop 1990;10(1):79-84.

[10] Mani GV, Hui PW, Cheng JC. Translation of the radius as a predictor of outcome in distal radial fractures of children. J Bone Joint Surg Br 1993;75(5):808-11.

[11] Miller BS, Taylor B, Widmann RF, et al. Cast immobilization versus percutaneous pin fixation of displaced distal radius fractures in children: a prospective, randomized study. J Pediatr Orthop 2005;25(4):490-4.

[12] Rodriguez-Merchan EC. Pediatric fractures of the forearm. Clin Orthop Relat Res 2005;432:65-72.

[13] Green JS, Williams SC, Finlay D, et al. Distal forearm fractures in children: the role of radiographs during follow up. Injury 1998;29(4):309-12.

[14] Haddad FS, Williams RL. Forearm fractures in children: avoiding redisplacement. Injury 1995;26(10):691-2.

[15] Bochang C, Jie Y, Zhigang W, et al. Immobilisation of forearm fractures in children: extended versus flexed elbow. J Bone Joint Surg Br 2005;87(7):994-6.

[16] Gupta RP, Danielsson LG. Dorsally angulated solitary metaphyseal greenstick fractures in the distal radius: results after immobilization in pronated, neutral and supinated position. J Pediatr Orthop 1990;10(1):90-2.

[17] Chess DG, Hyndman JC, Leahey JL, et al. Short arm plaster cast for distal pediatric forearm fractures. J Pediatr Orthop 1994;14(2):211-3.

[18] Bhatia M, Housden PH. Re-displacement of paediatric forearm fractures: role of plaster moulding and padding. Injury 2006;37(3):259-68.

[19] Debnath UK, Guha AR, Das S. Distal forearm fractures in children: cast index as predictor of re-manipulation. Indian J Orthop 2011;45(4):341-6. 
[20] Malviya A, Tsintzas D, Mahawar K, et al. Gap index: a good predictor of failure of plaster cast in distal third radius fractures. J Pediatr Orthop B 2007;16(1):28-52.
[21] Zamzam MM, Khoshhal KI. Displaced fracture of the distal radius in children: factors responsible for redisplacement after closed reduction. J Bone Joint Surg $\mathrm{Br}$ 2005;87(6):841-3. 